\title{
VESICOVAGINAL FISTULA (VVF): SUCCESS OF PRIMARY REPAIR.
}

\footnotetext{
1. MBBS, MCPS, FCPS

Professor

Department of O \& G DHQ Hospital/FMU, Faisalabad.

2. MBBS, MCPS, FCPS

Assistant Professor

Department of O \& G

DHQ Hospital/FMU, Faisalabad.

3. MBBS, FCPS

Assistant Professor

Department of O \& G

DHQ Hospital/FMU, Faisalabad.
}

Correspondence Address:

Dr. Ghazala Niaz

Department of O \& G

Faisalabad Medical University,

Faisalabad.

dr.ghazala.niaz@gmail.com

Article received on:

14/01/2019

Accepted for publication:

03/04/2019

\begin{abstract}
Robina Ali', Ghazala Niaz ${ }^{2}$, Riffat Ehsan ${ }^{3}$
ABSTRACT... Objectives: The main objective of this research is to determine success of primary repair of vesicovaginal fistula at tertiary care hospital. Study Design: Quasi Experimental. Setting: DHQ Hospital, Faisalabad, Obstetrics and Gynaecology Department. Period: From Mar 2015 to Mar 2017. Material \& Method: 15 patients were enrolled by consecutive sampling and those having fistulas more than $4 \mathrm{~cm}$ or involving ureteric orifice, bladder neck or urethra were excluded. After proper history examination, preliminary investigations and EUA, fistula repair was done. All information recorded on proposed proforma for this purpose. Results: Among all 15 patients, 10(66.7\%) were having obstetric fistulas and $5(33.3 \%)$ were with non obstetric fistula. $07(46.7 \%)$ had home delivery, $3(20 \%)$ had delivery at center by untrained persons, $3(20 \%)$ had hysterectomy by untrained surgeons i.e. $1(6.7 \%)$ for endometriosis, $1(6.7 \%)$ for multiple fibroids and $1(6.7 \%)$ for ovarian malignancy while $2(13.3 \%)$ patients had inducted miscarriages by midwives. $12(80 \%)$ patients had subtrigonal and trigonal fistulas, so underwent transvaginal repair and rest $3(20 \%)$ had supratrigonal fistula so transabdominal repair was done. Success of repair was $93.3 \%$ (14) and 1 was complicated with failed fistula repair. Conclusion: Most fistulas encountered in this study were caused by obstetrics trauma and are preventable. In existing cases of vesicovaginal fistula, properly trained health professionals with impeccable evaluation, prudent decision about route and technique of repair and good post operative care are key points in success of surgical repair.
\end{abstract}

Key words: $\quad$ Examination under anesthesia, Vesico vaginal fistula repair, Primary repair

Article Citation: Ali R, Niaz G, Ehsan R. Vesicovaginal Fistula (VVF): Success of primary repair. Professional Med J 2019; 26(12):2090-2094.

DOI: 10.29309/TPMJ/2019.26.12.3131

\section{INTRODUCTION}

Intrauterine VVF is an abnormal communication between the mucosa of the urinary bladder and that at vagina. This study was designed to evaluate success rate of primary repair of VVF among local population, resulting in significant improvement in quality of life of affected women. VVF (Vesiovaginal fistula) is an abnormal communication between the mucosa of the urinary bladder and that of the vagina. ${ }^{1}$ In developing countries most cases (> $90 \%$ ) result from complication of prolonged obstructed labour. ${ }^{2}$ The condition is extremely rare in developed world where majority of woman receive skilled obstetric care and early recourse to caesarean section prevents prolonged obstructed labour. ${ }^{3}$ In contrast in developed world, these fistulas usually follow pelvic surgeries (> 90\%) and rest by irradiation and malignancy. Regardless of its etiology, VVF has profound devastating consequences over patient's physical and psychological health. ${ }^{4}$ Most of these woman develop low self -esteem, depression and may become socially withdrawn. ${ }^{5,6}$ If the condition is not corrected promptly, on affected woman may be abandoned by her community, close relatives and even her husband. ${ }^{5,6}$ In extreme cases, she is treated as a social out cast and excommunicated from her community. ${ }^{6}$

Prevalence of VVF varies from country to country. Actual figures are impossible to determine because areas with highest overall prevalence are also those with poorest systems of health data collection. It may follow 1-2/1000 deliveries with an annual world wide incidence of upto 500,000 cases. $^{7}$ Developing countries lack sufficient functioning maternity centers and woman often fail to utilize available maternity 
services, therefore, the VVF with its devastating impact will continue to occur. ${ }^{5,6}$ Some woman in Pakistan avoid hospital confinement due to poverty, illiteracy and ignorance, being unaware of the dangers of delivering under supervision of unskilled birth attendants. VVF may be simple or complicated. Simple small fistulas may be managed conservatively via catheterization for 19-54 days with success rate of $2-30 \%{ }^{8}$ Surgery is the mainstay of treatment and regardless of the route principles that underlie VVF repair remain the same i.e, repair should be tension free, water tight and uninfected. ${ }^{8}$ Overall success rate of VVF repair in different series was found to be $98 \%$ in terms of cure at first operation. The success found with vaginal route varies from $83-100 \%$ and with abdominal route $86-100 \%$ so there was no significant difference between two routes. ${ }^{9,10}$ Health is defined not only as the absence of infirmity but also as a state of physical mental and social wellbeing. Vesicovaginal fistula with its devastating effects on the woman's personal hygiene, self esteem, interpersonal relationships and environment disrupts all three elements of her health. This study was designed to evaluate success rate of primary repair of VVF among local population, resulting in significant improvement in quality of life of affected females.

\section{MATERIAL AND METHOD}

This was Quasi Experimental type of study carried out at obstetrics and gynecology department of DHQ Hospital, Faisalabad from March 2015 to March 2017. Total of 15 patients with VVF were collected by consecutive sampling technique. Those patients who had lager fistula more than $4 \mathrm{~cm}$ or fistula involving ureteric orifice, bladder neck or urethra were excluded from study. Selected patients were evaluated to collect data regarding age, parity, cause of fistula, place of delivery in case of obstetric fistula; indication of pelvic surgery if it was causative agent or any other cause involved. Afterwards examination under anesthesia was done to determine type of fistula, its position, size, mobility and surrounding tissue health. Preliminary investigations were done and then sugary was performed either by Trans abdominal or transvaginal route. All information was collected on proposed Performa designed for this purpose including demographic variables, route and success of repair. Data analysis was done by using SPSS version 20. Mean and standard deviation were determined for demographic variables and frequencies were determined for other variables.

\section{RESULTS}

Total number of patients were 15 and yearly distribution was as under"

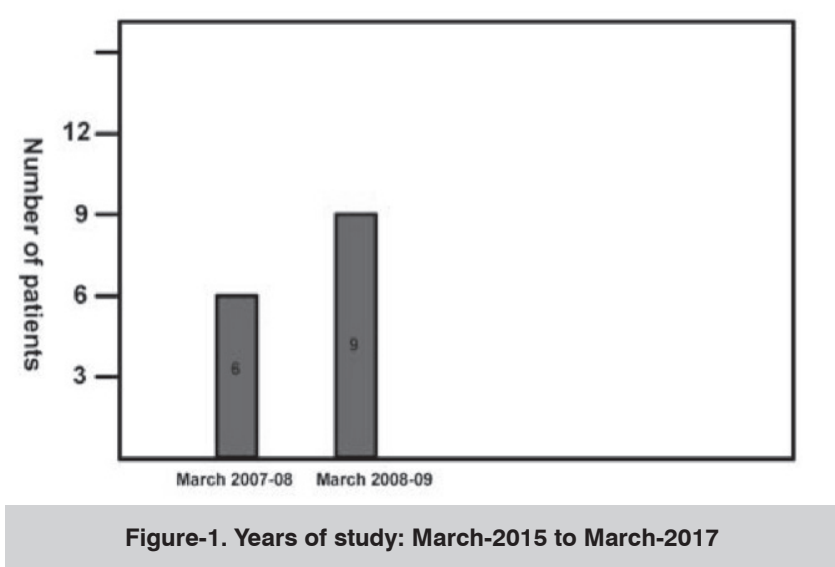

Yearly Distribution of Patients:

Demographic variables like age and parity with their mean and standard deviation were shown in Table-I.

\begin{tabular}{|c|c|c|c|c|c|}
\hline & $\mathbf{n}$ & Minimum & Maximum & Mean & $\begin{array}{c}\text { Std. } \\
\text { Deviation }\end{array}$ \\
\hline \multirow{2}{*}{$\begin{array}{l}\text { Age } \\
\text { of the } \\
\text { patient } \\
\text { parity }\end{array}$} & 15 & 17 & 41 & 28.27 & 6.75 \\
\hline & 15 & 0 & 8 & 3.40 & 2.26 \\
\hline
\end{tabular}

Among all these patients 10 (66.7\%) patients were having obstetric cause for fistulas and 5(33\%) were having non-obstetric fistulas as shown in Figure-2 and Table-II. 


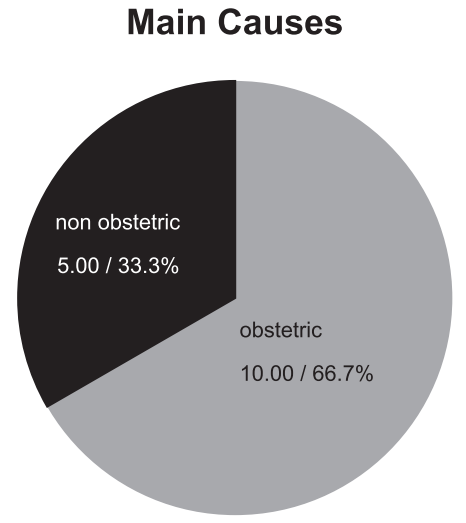

Figure-2: Distribution of patients according to cause of fistulas

\begin{tabular}{|l|c|c|}
\hline & Frequency & Percent \\
\hline Obstetric & 10 & 66.7 \\
\hline Non obstetric & 5 & 33.3 \\
\hline Total & 15 & 100.0 \\
\hline Table-II. Distribution of patients according to cause of \\
fistulas
\end{tabular}

$7(46.7 \%)$ patients were having unsupervised home delivery as main risk factors for developing fistulas, $3(20 \%)$ were having delivery at center by untrained personnel, $1(6.7 \%)$ was having surgery for endometriosis, $1(6.7 \%)$ was having hysterectomy for multiple fibroids, $1(6.7 \%)$ was having hysterectomy for ovarian malignancy, 2 (13.3\%) patients were having induced miscarriages as in Figure-3, Table-III.

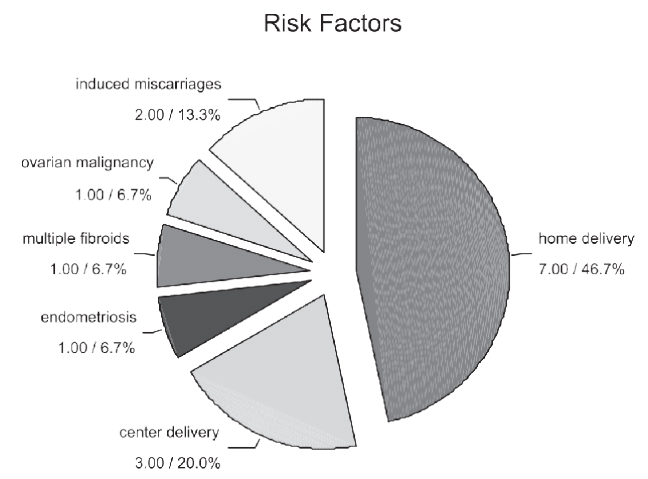

Figure-3. Distribution of patients according to risk factors

12 (80\%) patients were having subtrigonal or trigonal fistulas and $3(20 \%)$ were having supratrigonal fistulas. (Figure-4)

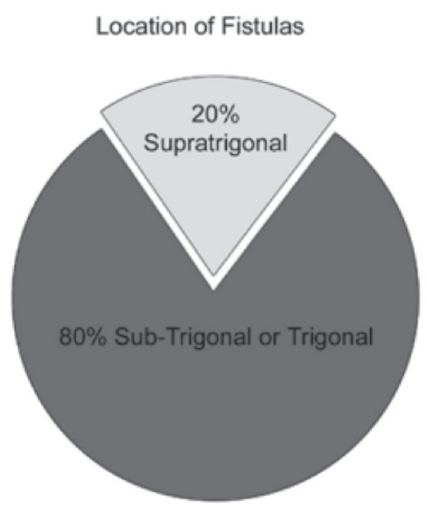

Figure-4. Distribution of patients according to location of fistulas

12 (80\%) underwent transvaginal repair and $3(20 \%)$ had transabdominal repair. (Figure-5)

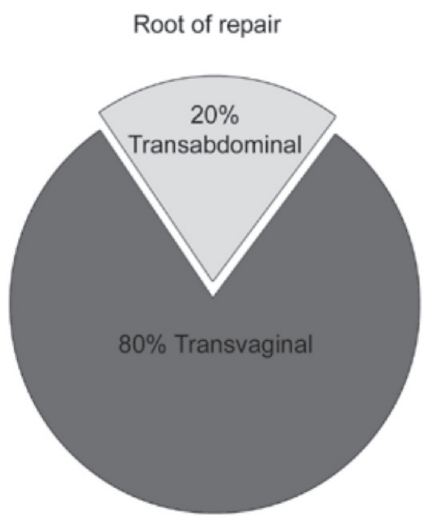

Figure-5. Distribution of patients according to root of repair of fistulas

Success of repair was $14(93.3 \%)$ and only one patient had complication of failed fistulas repair.

\section{success of repair}

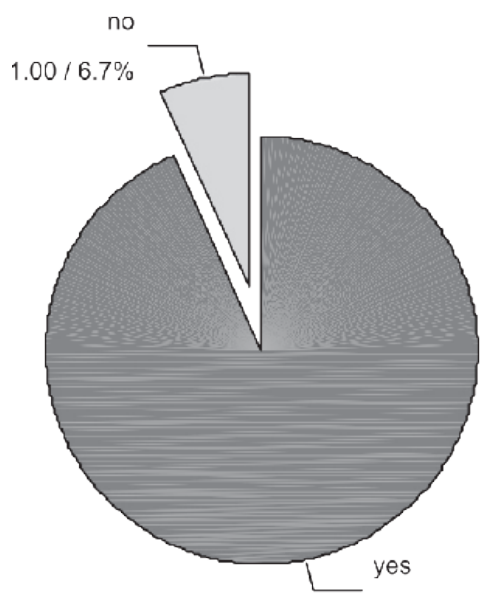

$14.00 / 93.3 \%$ 


\section{DISCUSSION}

Vesicovaginal fistulas are amongst the most distressing, socially debilitating problem having important implications for the life of affected woman. In my study, age of the affected patients was between 17-41 years with mean age of 28.27 ( \pm 6.75 years). This age group of females is comparable to patients in a study conducted at Ethopia with age between 12-45 years and mean age of 25( \pm 6$)$ years. In contrast to the western world obstetric fistulas remain a major cause of vesicovaginal fistula in many underdeveloped countries including ours ${ }^{9,10}$ This shows low standards of antenatal and obstetric care. In this study $66.7 \%$ patients were having obstetric fistulas similar to some local and international studies ${ }^{11,12}$ In another study conducted at a tertiary care hospital of west Bangal, $66 \%$ cases of VVF were tracked back to their obstetric causes and $34 \%$ patients could be linked up to gynaecological etiology like a complication of hysterectomy or after brachytherapy for carcinoma of cervix. ${ }^{13}$ Among the 10 patients having obstetric fistulas, 7 were having home delivery and 3 were having delivery at some center by untrained personnel. This again is in sharp comparison to some of studies cited above. ${ }^{9,10,12}$ In this study only 3 patients out of $15(20 \%)$ were having fistulas after different gynecological procedures. This is in contrast to results of various studies done at developed countries where $90 \%$ of fistulas were caused by iatrogenic injuries during different pelvic surgeries. ${ }^{8}$ These $20 \%$ fistulas were created mainly due to surgeries by untrained persons in cases where proper surgical expertise was needed.

In my study, $80 \%$ patients were having trigonal or subtrigonal fistulas, so underwent transvaginal repair. Only $20 \%$ patients were having supratrigonal fistulas and had transabdominal repair done. In another study done at Ethiopia regarding characteristics and repair outcome of patients with vesicovaginal fistula, transvaginal repair was done in 161 patients out of 168 patients $(95.8 \%) .{ }^{14}$ In my study, 14 cases had successful surgery out of 15 cases which is $93.3 \%$. In another study conducted at Muzaffarabad, Azad Kashmir,
24 cases out of 26 had successful repair at time primary surgery thus giving a success rate of $92.31 \%$ which is comparable to my study.${ }^{15}$ While another study conducted at tertiary case hospital of west Bengal Showed a bit lower success rate of $87.3 \% .{ }^{13}$ Another study conducted at Jimma university teaching hospital Ethiopia showed a success rate of $93.4 \%$ which is again comparable to my study. ${ }^{14}$

\section{CONCLUSION}

Most fistula patients in this study had obstetric fistula which is largely preventable. "Every woman counts" should be our aim for provision of standard maternal health services. Increasing access to comprehensive emergency obstetric care is essential to minimize the delay contributing to perinatal mortality and obstetric fistulas. In existing cases of vesicovaginal fistula, properly trained health professional with impeccable evaluation, prudent decision about route and technique of repair and good postoperative care are key points in success of surgical repair.

\section{Copyright@ 03 Apr, 2019.}

\section{REFERENCES}

1. Umoiyoho AJ, Inyang. Etoh EC, Abah GM, Abasiattai AM, Akaiso OE. Quality of life following successful repair of vesicovaginal fistula in Nigeria. Rural and Remote Health 2011; 11:1734-40.

2. Garza CR, Clavijo R, Sotelo R. Laparoscopic treatment of urogenital fistulae. Arch ESP Urol 2012; 65:659-72.

3. Nielsen HS, Lindberg L, Nygaard U, Aytenfisu $H$, Johnston OL, Sovensen B, Rudnicki M, Crangle M, Lawson R, Duffy S. A community based long term follow up of women undergoing obstetric fistula repair in rural Ethopia. BJOG 2009; 116:1258-64.

4. Hilton P, Cromwell D. The risk of vesicovaginal and urethrovaginal fistula after hysterectomy performed in English National Health Service. A retrospective cogort study examining patterns of care between 2000 and 2008.BJOG 2012; 119:1447-54.

5. Karshinia JA, Otubu JAM. Fistula In: Agboola A (Ed.) Textbook of obstetrics and gynaecology for medical students. Nigeria: Heinemann Educational; 2006:3951.

6. Danso KA. Genital tract fistulas. In:Kwawukume EY, Emuveyan EE(Eds). Comprehensive gynaecology in the tropics. Accra 2005; 174-81. 
7. Hilton $P$. Vesocovaginal fistulas in developing countries Int. J Gynecol Obstet 2003; 82:285-95.

8. Zhang Q, Ye Z, Liu F, Qi X, Sao C, He X, et al. Laparoscopic transabdominal transvesical repair of supratrigonal vesicovaginal fistula. Int Urogynecol J 2013; 24:337-42.

9. Rashid $Y$, Majeed T, Majeed N, Shehzad N. latrogenic vesicovaginal fistula. J Coll physicians Surg Pak. 2010; 20:436-8.

10. Rasool M, Tabassum SA, Mumtaz F. Vesico-vaginal fistula repair: Urologist experience at Bahawalpur. Professional Med J. 2006;13:445-52.

11. Hilton $P, W a r d A$. Epidemiological and surgical aspects of urogenital fistul: A review of 25 years experience in South-West Nigeria. Int Urogynecol J Pelvic Floor Dysfunct 1998; 9:189-94.
12. Hilton P. Surgical fistula. In: Cardozo LD, Staskin $D$, editors. Textbook of female urology and urogynaecology. London: Taylor \& Francis; 2001:691710.

13. Datta B, Chattopadhyyays, Mendal M. Vesicovaginal fistula: Our experience of 47 caes in a tertiary care hospital of West Bengal. J. Evolution Med. Dent. Sci. 2016; 5 (47)2952-4.

14. Sori DA, Azale AW, Gemeda DH. Characteristics and repair outcome of patients with vesicovaginal fistula managed in Jimma University Teaching Hospital, Ethopia. BMC Urol. 2016; 16:41-8.

15. Shakil M, Ahmad R, Hamid S. Surgical outcomes of genitourinary fistulae: an analysis of 26 cases Pak J Physical 2016; 12(4):27-9.

\begin{tabular}{|c|c|c|c|}
\hline \multicolumn{2}{|c}{ AUTHORSHIP AND CONTRIBUTION DECLARATION } \\
\hline Sr. \# & Author(s) Full Name & \multicolumn{1}{|c|}{ Contribution to the paper } & Author(s) Signature \\
\hline 1 & Robina Ali & $\begin{array}{l}\text { Help in conceptualizaing } \\
\text { the project and review the } \\
\text { document for error. } \\
\text { Data collection and prepare the } \\
\text { manuscirpt. } \\
\text { Provide Statistical analysis. }\end{array}$ \\
\hline 3 & Riffat Ehsan & Ghazala Niaz & \\
\hline
\end{tabular}

